The Israeli Journal of Aquaculture - Bamidgeh, IJA_69.2017.1451, 9 pages

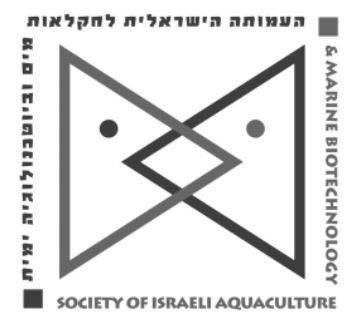

The IJA appears exclusively as a peer-reviewed on-line open-access journal at http://www.siamb.org.il. To read papers free of charge, please register online at registration form.

Sale of IJA papers is strictly forbidden.

\title{
Effects of Dietary Phosphorus Levels on Growth Performance, Plasma Biochemical Parameters, and Relative Gene Expression of Lipogenesis of Bighead Carp, Aristichthys nobilis
}

\author{
Ke $\mathrm{Ji}^{1}$, Hualiang Liang ${ }^{1}$, Haifeng $\mathrm{Mi}^{2}$, Ahmed Mokrani ${ }^{1}$, Jun $\mathrm{Xie}^{1,2}$, \\ Bo Liu' ${ }^{1,2}$, Xianping Ge ${ }^{1,2 *}$, Mingchun Ren ${ }^{1}{ }^{2 *}$ \\ ${ }^{1}$ Wuxi Fisheries College, Nanjing Agricultural University, Wuxi 214081, \\ China; \\ ${ }^{2}$ Key Laboratory for Genetic Breeding of Aquatic Animals and Aquaculture \\ Biology, Freshwater Fisheries Research Center (FFRC), Chinese Academy \\ of Fishery Sciences (CAFS), Wuxi 214081, China.
}

Keywords: bighead carp; phosphorus; growth; requirement; gene expression.

\begin{abstract}
An 8-week feeding trial was conducted to investigate the effects of dietary phosphorus levels on growth performance, plasma biochemical parameters, and lipogenesis gene expression of bighead carp. The results showed that weight gain (WG) and specific growth rate (SGR) increased with increasing dietary phosphorus levels up to $1.12 \%$, and after that decreased. Feed conversion ratio (FCR) showed a converse trend compared with WG. Whole body protein and lipid contents significantly increased and decreased with increasing dietary phosphorus levels, respectively $(P<0.05)$, whereas moisture and ash contents were not significantly affected by the dietary phosphorus levels $(P>0.05)$. The highest values of the hepatosomatic index (HSI), total protein, and albumin contents were observed with $1.12 \%$ dietary phosphorus supplementation $(P<0.05)$. Glucose levels increased with dietary phosphorus up to the level $1.32 \%$ phosphorus supplementation, and then decreased. Serum total cholesterol, total triglyceride, aspartate aminotransferase, alanine aminotransferase, and alkaline phosphates activity were not significantly affected by dietary phosphorus levels $(P>0.05)$. Excess phosphorus levels $(1.32 \%$ and $1.59 \%)$ significantly down-regulated the relative gene expression levels of sterol regulatory element binding protein (SREBP) -1 and fatty acid synthase (FAS) $(P<0.05)$. Based on WG and FCR, the optimal dietary phosphorus level should be $1.16 \%$, using quadratic regression analysis.
\end{abstract}

\footnotetext{
*Corresponding authors: Xianping Ge, E-mail: gexp@ffrc.cn
}

Mingchun Ren, E-mail: renmc@ffrc.cn 


\section{Introduction}

As with terrestrial vertebrates, phosphorus is one of the most important AND abundant minerals for aquatic species (Lall, 2002). Phosphorus is essential for normal growth and bone mineralization (Watanabe et al., 1988). It is also a constituent of nucleic acids, cell membranes, and the structural components of skeletal tissues, and is directly involved in all energy producing cellular reactions (NRC, 1993). Furthermore, phosphorus plays an important role in metabolic processes, carbohydrate, lipid, and nitrogen metabolism, and helps maintain a stable buffer system in body fluids (Lovell, 1989; Lall, 2002). Phosphorus requirements have been determined for many aquatic species, such as tilapia hybrids Oreochromis niloticus $\times$ O. aureus (Zhang et al., 2015), carp Cyprinus carpio L. (Ogino and Takeda, 1976), large yellow croaker Pseudosciaena crocea R (Mai et al., 2006), Atlantic salmon Salmo salar L. (Åsgård and Shearer, 1997) and channel catfish (Ictalurus punctatus (Wilson et al., 1982).

Fish can absorb minerals from the surrounding water (NRC, 1993). However, the concentration of phosphorus in natural waters and the absorption rate of phosphorus from the water is limited (Boyd, 1971; Shao et al., 2008; Mai et al., 2006) and fish must obtain most phosphorus from their diets to maintain normal physiological activities (Liang et al., 2012). Some studies have indicated that adequate phosphorus levels increase growth and decrease lipid content in fish (Sakamoto and Yone, 1978; Eya and Lovell, 1997). However, overdoses of phosphorus in practical diets and phosphorus excreted from cultured animals into water lead to eutrophication of aquaculture environments and decrease water quality (Beveridge, 1984; Kim et al., 1998). It is therefore important to determine the optimal supplementation of dietary phosphorus for economy and environment (Mai et al., 2006; Liang et al., 2012).

Bighead carp (Aristichthys nobilis) are very important freshwater fish for commercial aquaculture in China (Tong and Sun, 2015). This species is a water column filter feeder relying on plankton and detritus. It is used to control water quality (Lieberman, 1996). In practical aquaculture, bighead carp are generally fed commercial diets to improve growth performance. The aim of this study was to determine the dietary phosphorus requirement for bighead carp and the effects of dietary phosphorus levels on growth performance, whole body composition, plasma biochemistry, and relative gene expression of lipogenesis.

\section{Materials and methods}

Diet preparation. Six isonitrogenous and isoenergetic practical diets were formulated to contain graded phosphorus levels $(0.49 \%, 0.71 \%, 0.90 \%, 1.12 \%, 1.32 \%$ and $1.59 \%$ of dry diet), together with phosphorus from dietary ingredients and monocalcium phosphate (Table 1). Fishmeal was the source of dietary protein. All ingredients were ground into powder, passed through a 60-mesh sieve, mixed uniformly with soybean oil and water and extruded with an extruder (Wuxi Tongwei Feed Co. Ltd.). It was then dried at $45^{\circ} \mathrm{C}$ and stored at $-20^{\circ} \mathrm{C}$ for further use.

Experimental procedure. Bighead carp were obtained from the breeding farm of Freshwater Fisheries Research Center (FFCR) of Chinese Academy of Fishery Sciences. Before the feeding trial, the fish were starved for $24 \mathrm{~h}$. Healthy fish of similar sizes were selected, and reared in cages $(2 \mathrm{~m} \times 1 \mathrm{~m} \times 1 \mathrm{~m})$, and fed with a commercial floating feed containing $31.6 \%$ protein and $6.6 \%$ lipid (Wuxi Tongwei feedstuffs Co. Ltd., Wuxi China) for two weeks to acclimatize to environmental conditions. Fish with an initial weight of $223.55 \pm 0.17 \mathrm{~g}$ were randomly sorted into eighteen cages (10 fish per cage). Each diet was randomly assigned to triplicate cages for 8 weeks. Fish were hand-fed three times daily at 8:00, 12:00, and 16:00 until apparent satiation. During the experimental period, water temperature ranged from $26-28^{\circ} \mathrm{C}, \mathrm{pH}$ from $7.3-7.8$, ammonia nitrogen was lower than $0.05 \mathrm{mg} / \mathrm{L}$, and dissolved oxygen was not less than $6.0 \mathrm{mg} / \mathrm{L}$.

Sample collection and chemical analysis. At the end of the feeding trial, six experimental bighead carp from each cage were sampled, anesthetized with $100 \mathrm{mg} / \mathrm{L}$ MS-222, and weighed. Blood samples were collected from the caudal vein with disposable 
medical syringes and separated by centrifugation $\left(3500 \times \mathrm{g}, 10 \mathrm{~min}, 4^{\circ} \mathrm{C}\right)$. Liver samples were collected and weighed. These were stored at $-80^{\circ} \mathrm{C}$ until analysis. Another three fish per cage were sampled and stored at $-20^{\circ} \mathrm{C}$ for whole body composition analysis. Individual body weight and liver weight were recorded to calculate their condition factor and hepatosomatic index.

Moisture, crude protein, crude lipid and ash content were analyzed. Dry matter was determined by drying the feeds and fish in an oven at $105^{\circ} \mathrm{C}$ until constant weight; crude protein $(\mathrm{N} \times 6.25)$ was analyzed by Kjeldahl method after acid digestion; lipid was analyzed by ether extraction using Soxhlet; ash by combustion at $550^{\circ} \mathrm{C}$ for $5 \mathrm{~h}$. Duplicate analyses were conducted for each sample.

Table 1. Ingredient and nutrient composition of experimental diets (\% dry basis)

\begin{tabular}{|c|c|c|c|c|c|c|}
\hline \multirow{2}{*}{ Ingredients } & \multicolumn{6}{|c|}{ Diets } \\
\hline & 1 & 2 & 3 & 4 & 5 & 6 \\
\hline Fish meal $^{1}$ & 5 & 5 & 5 & 5 & 5 & 5 \\
\hline Rapeseed meal $^{1}$ & 27 & 27 & 27 & 27 & 27 & 27 \\
\hline Soybean meal ${ }^{1}$ & 26 & 26 & 26 & 26 & 26 & 26 \\
\hline Cottonseed meal ${ }^{1}$ & 7.55 & 7.55 & 7.55 & 7.55 & 7.55 & 7.55 \\
\hline Wheat meal ${ }^{1}$ & 26.79 & 26.19 & 25.59 & 24.99 & 24.39 & 23.79 \\
\hline Fish oil & 5 & 5 & 5 & 5 & 5 & 5 \\
\hline Choline chloride & 0.1 & 0.1 & 0.1 & 0.1 & 0.1 & 0.1 \\
\hline Vitamin C & 0.1 & 0.1 & 0.1 & 0.1 & 0.1 & 0.1 \\
\hline Vitamin premix ${ }^{2}$ & 1 & 1 & 1 & 1 & 1 & 1 \\
\hline Mineral premix ${ }^{3}$ & 1 & 1 & 1 & 1 & 1 & 1 \\
\hline Ethoxyquin & 0.01 & 0.01 & 0.01 & 0.01 & 0.01 & 0.01 \\
\hline Monocalcium phosphate & 0 & 0.6 & 1.2 & 1.8 & 2.4 & 3.0 \\
\hline Trimethylamine oxide & 0.15 & 0.15 & 0.15 & 0.15 & 0.15 & 0.15 \\
\hline L-glycine & 0.3 & 0.3 & 0.3 & 0.3 & 0.3 & 0.3 \\
\hline \multicolumn{7}{|c|}{ Analyzed proximate composition } \\
\hline Crude protein & 31.90 & 31.35 & 31.81 & 31.18 & 31.71 & 32.04 \\
\hline Crude lipid & 6.63 & 6.70 & 6.64 & 6.91 & 6.59 & 6.51 \\
\hline Phosphorus & 0.49 & 0.71 & 0.90 & 1.12 & 1.32 & 1.59 \\
\hline
\end{tabular}

${ }^{1}$ Fish meal, obtained from obtained from Wuxi Tongwei feedstuffs Co., Ltd, Wuxi, China, crude protein $61.3 \%$, crude lipid 10.2\%; Rapeseed meal, obtained from Wuxi Tongwei feedstuffs Co., Ltd, Wuxi, China, crude protein 37.54\%, crude lipid 1.4\%; Soybean meal, obtained from Wuxi Tongwei feedstuffs Co., Ltd, Wuxi, China, crude protein $44.17 \%$, crude lipid $1.1 \%$; Cottonseed meal, obtained from Wuxi Tongwei feedstuffs Co., Ltd, Wuxi, China, crude protein 49.32\%, crude lipid $1.4 \%$; Wheat meal, obtained from Wuxi Tongwei feedstuffs Co., Ltd, Wuxi, China, crude protein $11 \%$, crude lipid $1.2 \%$.

${ }^{2}$ Vitamins premix (IU or $\mathrm{mg} \mathrm{kg}^{-1}$ of dry diet): vitamin A, $25000 \mathrm{IU}$; vitamin D3, 20000 IU; vitamin $\mathrm{E}$, $200 \mathrm{mg}$; vitamin $\mathrm{K} 3,20 \mathrm{mg}$; thiamin, $40 \mathrm{mg}$; riboflavin, $50 \mathrm{mg}$; pyridoxine $\mathrm{HCl}, 40 \mathrm{mg}$; cyanocobalamin, $0.2 \mathrm{mg}$; biotin, 6mg; folic acid, $20 \mathrm{mg}$; niacin, 200mg; inositol, 1000mg.

${ }^{3}$ Mineral premix ( $\mathrm{mg}$ or $\mathrm{g} \mathrm{kg}^{-1}$ of dry diet): calcium pantothenate, $100 \mathrm{mg}$; sodium chloride, 2.6; potassium chloride, $5 \mathrm{~g}$; magnesium sulphate, $2 \mathrm{~g}$; ferrous sulphate, $0.9 \mathrm{~g}$; zinc sulphate, $0.06 \mathrm{~g}$; cupric sulphate, 0.02 ; manganese sulphate, $0.03 \mathrm{~g}$; sodium selenate, $0.02 \mathrm{~g}$; cobalt chloride, $0.05 \mathrm{~g}$; potassium iodide, $0.004 \mathrm{~g}$.

Plasma aspartate aminotransferase (AST), alanine transaminase (ALT), albumin (ALB), total protein (TP), Glucose (GLU), total cholesterol (TC), total triglyceride (TG), and alkaline phosphates (ALP) were measured by an automatic biochemical analyzer Mindary BS-400 (Shenzhen, China) using assay kits purchased from Shenzhen Mindary 
Bio-medical Electronics Co., Ltd., following previously described method (Liu et al., 2012; Wang et al., 2014).

Relative gene expression levels of sterol regulatory element binding protein (SREBP) 1 and fatty acid synthase (FAS) were determined using Real-time PCR analysis. Firstly, total RNA was extracted from the liver of juvenile bighead carp using a RNAiso plus kit (Takara, Dalian, China). After quality and quantity of RNA were checked, complementary DNA (cDNA) was synthesized using a PrimeScript TM RT reagent kit (Takara, Dalian, China). Specific primers for SREBP1, $\beta$-actin and FAS genes were: primer sequences of SREBP1: 5'-ACAACAGTAGCGACACCCTG-3' and 5'-AGGAGCGGTAGCGTTTTTCA-3'; primer sequences of $\beta$-actin: $5^{\prime}$-TCGTCCACCGCAAATGCTTCTA-3' and ${ }^{\prime}$ 'CCGTCACCTTCACCGTTCCAGT-3'; primer sequences of FAS: $5^{\prime}$ GTTTGCCAACCGCTTGTCTT- ${ }^{\prime}$ and 5'-GGCCATGGCGAATAGCATTG-3'. $\beta$-actin was employed as a non-regulated reference gene, we found no changes in our studies. Relative quantification of target gene expression was performed using the Pfaffl's mathematical model (Pfaffl, 2001).

Statistics analysis. Parameters were calculated as follows:

Specific growth rate (SGR) $(\% /$ day) $=100 \times$ [ (In (final body weight $(\mathrm{g})$ ) - In (initial body weight $(\mathrm{g}))$ )/days]

Feed conversion ratio (FCR) $=$ dry feed fed $(\mathrm{g}) /$ wet weight gain $(\mathrm{g})$

Weight gain (WG) $(\%)=100 \times$ (final weight $(\mathrm{g})$-initial weight $(\mathrm{g}))$ /initial weight $(\mathrm{g})$ Hepatosomatic index (HSI) $(\%)=100 \times$ (liver weight $(\mathrm{g}) /$ body weight $(\mathrm{g})$ )

All data were subjected to one-way analysis of variance (ANOVA) using the SPSS 16.0 software for Windows. Significant differences between means were evaluated by Multiple Range Test. Probabilities of $P<0.05$ were considered significant. Data are expressed as means with SEM. The quadratic regression model was used to estimate the optimum dietary phosphorus requirement on the basis of WG and FCR.

\section{Results}

Growth performance. Results of growth performance of the bighead carp are shown in Table 2. Final weight (FW), weight gain (WG), specific growth rate (SGR), increased significantly with dietary phosphorus levels from $0.49 \%$ to $1.12 \%$ diet, and then decreased when the phosphorus content increased $(P<0.05)$. Feed conversion ratio (FCR) showed a converse trend compared with WG and SCR. The hepatosomatic index (HSI) in the fish fed with $1.12 \%$ phosphorus diet was highest, and significantly higher than those fed $0.49 \%$ and $0.71 \%$ phosphorus diet $(P<0.05)$. Based on WG and FCR, the optimal dietary phosphorus level for bighead carp was $1.16 \%$ of the diet (Figs. $1 \& 2$ ), using quadratic regression analysis.

Table 2. Growth performance of bighead carp fed with the experimental diets (Means \pm S.E.M.) ${ }^{1}$

\begin{tabular}{lllllll}
\hline Diet & Initial Weight $(g)$ & Final Weight $(g)$ & $S G R^{2}(\% /$ day $)$ & $W G^{3}(\%)$ & $F C R^{4}$ & $H S I^{5}(\%)$ \\
\hline 1 & $222.60 \pm 0.60$ & $389.90 \pm 0.70^{\mathrm{a}}$ & $1.00 \pm 0.01^{\mathrm{a}}$ & $52.70 \pm 0.73^{\mathrm{a}}$ & $1.63 \pm 0.01^{\mathrm{c}}$ & $0.76 \pm 0.06^{\mathrm{a}}$ \\
2 & $223.60 \pm 0.30$ & $394.45 \pm 0.25^{\mathrm{ab}}$ & $1.01 \pm 0.01^{\mathrm{a}}$ & $54.05 \pm 0.09^{\mathrm{a}}$ & $1.59 \pm 0.01^{\mathrm{bc}}$ & $0.80 \pm 0.07^{\mathrm{a}}$ \\
3 & $223.20 \pm 0.70$ & $405.90 \pm 3.10^{\mathrm{bc}}$ & $1.07 \pm 0.01^{\mathrm{ab}}$ & $59.45 \pm 0.89^{\mathrm{ab}}$ & $1.44 \pm 0.04^{\mathrm{ab}}$ & $0.96 \pm 0.09^{\mathrm{ab}}$ \\
4 & $223.13 \pm 0.41$ & $412.10 \pm 2.23^{\mathrm{c}}$ & $1.10 \pm 0.01^{\mathrm{b}}$ & $62.28 \pm 0.89^{\mathrm{b}}$ & $1.36 \pm 0.01^{\mathrm{a}}$ & $1.20 \pm 0.07^{\mathrm{bc}}$ \\
5 & $223.43 \pm 0.52$ & $407.70 \pm 7.37^{\mathrm{bc}}$ & $1.07 \pm 0.04^{\mathrm{ab}}$ & $60.11 \pm 3.67^{\mathrm{ab}}$ & $1.43 \pm 0.07^{\mathrm{ab}}$ & $1.13 \pm 0.09^{\mathrm{c}}$ \\
6 & $223.93 \pm 1.33$ & $400.77 \pm 3.26^{\mathrm{abc}}$ & $1.04 \pm 0.02^{\mathrm{ab}}$ & $56.65 \pm 1.75^{\mathrm{ab}}$ & $1.53 \pm 0.04^{\mathrm{bc}}$ & $1.09 \pm 0.07^{\mathrm{bc}}$
\end{tabular}

${ }^{1}$ Data are means of triplicate; means in the same column sharing the same superscript letter are not significantly different determined by Tukey's test $(P>0.05)$.

${ }^{2}$ Specific growth rate $(\mathrm{SGR})\left(\%\right.$ day $\left.^{-1}\right)=100 \times[$ (In (final body weight $(\mathrm{g})$ ) - In (initial body weight (g)))/ days]

${ }^{3}$ Weight gain $(W G)(\%)=100 \times($ final weight $(g)$-initial weight $(\mathrm{g}))$ /initial weight $(\mathrm{g})$

${ }^{4}$ Feed conversion ratio $(F C R)=$ dry feed fed $(\mathrm{g}) /$ wet weight gain $(\mathrm{g})$

${ }^{5}$ Hepatosomatic index $(\mathrm{HSI})(\%)=100 \times($ liver weight $(\mathrm{g}) /$ body weight $(\mathrm{g}))$ 


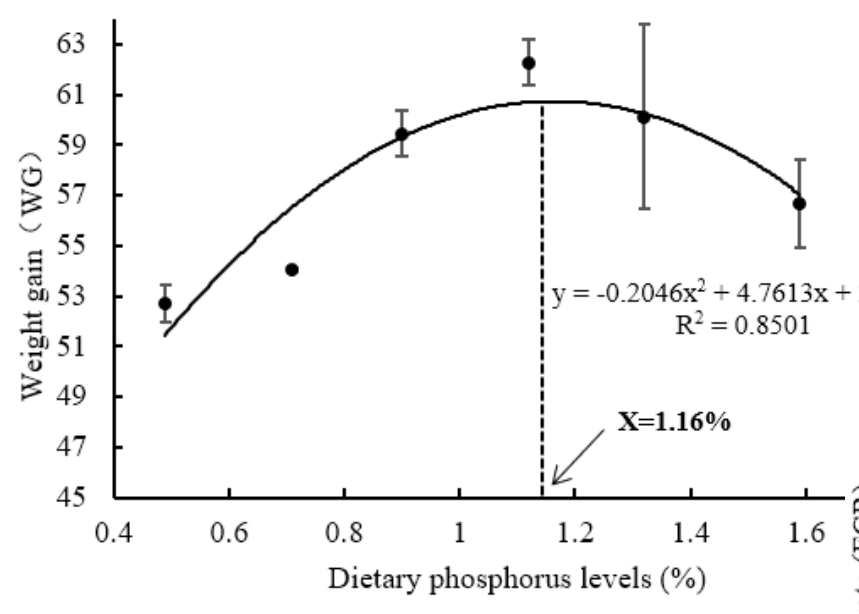

Figure 2. Quadratic regression analysis of feed conversion rate (FCR) against varying dietary phosphorus levels.

Figure 1. Quadratic regression analysis of weight gain (WG, \%) against varying dietary phosphorus levels.

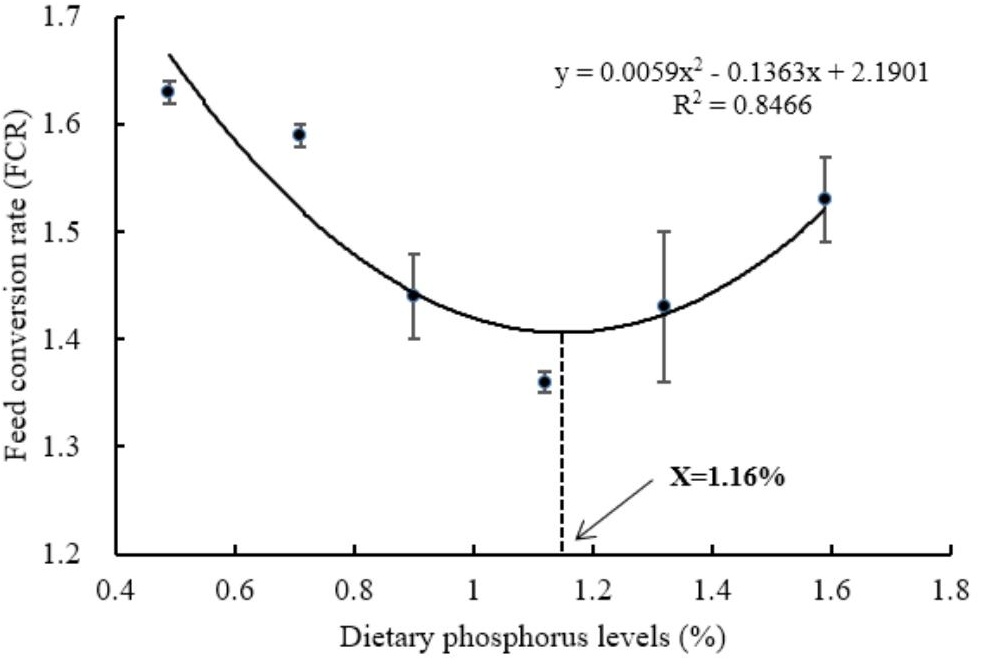

Whole body composition. Whole body composition is presented in Table 3 . Whole body protein increased with the increasing phosphorus level up to $1.59 \%$, but whole body lipid content was minimized when in the level was $1.59 \%$, and was significantly lower than in other groups $(P<0.05)$. Whole body moisture and ash content of bighead carp were not significantly affected by the graded dietary phosphorus levels $(P>0.05)$.

Table 3. Whole body composition of bighead carp fed with the experimental diets (Mean \pm S.E.M.) ${ }^{1}$

\begin{tabular}{lllll}
\hline Diet & Moisture (\%) & Protein (\%) & Lipid (\%) & Ash (\%) \\
\hline 1 & $78.63 \pm 1.0$ & $13.22 \pm 0.2^{\mathrm{a}}$ & $3.96 \pm 0.2^{\mathrm{b}}$ & $4.12 \pm 0.2$ \\
2 & $78.06 \pm 0.9$ & $13.84 \pm 0.5^{\mathrm{ab}}$ & $4.00 \pm 0.1^{\mathrm{b}}$ & $4.08 \pm 0.1$ \\
3 & $77.93 \pm 0.9$ & $14.34 \pm 0.2^{\mathrm{ab}}$ & $3.96 \pm 0.1^{\mathrm{b}}$ & $3.72 \pm 0.1$ \\
4 & $77.92 \pm 1.0$ & $14.45 \pm 0.2^{\mathrm{ab}}$ & $3.84 \pm 0.2^{\mathrm{b}}$ & $3.81 \pm 0.3$ \\
5 & $77.69 \pm 1.0$ & $15.07 \pm 0.3^{\mathrm{bc}}$ & $3.61 \pm 0.1^{\mathrm{b}}$ & $3.69 \pm 0.1$ \\
6 & $76.91 \pm 1.0$ & $16.17 \pm 0.2^{\mathrm{c}}$ & $2.53 \pm 0.1^{\mathrm{a}}$ & $4.44 \pm 0.4$ \\
\hline
\end{tabular}

${ }^{1}$ Data are means of triplicate; means in the same column sharing the same superscript letter are not significantly different determined by Tukey's test $(P>0.05)$.

Plasma biochemical parameters. Plasma biochemistry is presented in Table 4. Total protein (TP) and albumin (ALB) content was maximized when the dietary phosphorus level was $1.12 \%$, but was significantly higher than those fed $0.49 \%, 0.71 \%$, and $1.59 \%$ dietary phosphorus $(P<0.05)$. Glucose (GLU) content increased when dietary phosphorus level was up to $1.32 \%$, and then decreased $(P<0.05)$. The content of serum total cholesterol (TC) and total triglyceride (TG) activities increased with increasing dietary phosphorus levels up to $0.90 \%$, and thereafter showed a decreasing trend. Aspartate aminotransferase (AST), and alanine aminotransferase (ALT) were not significantly affected by dietary phosphorus levels $(P>0.05)$. Alkaline phosphates (ALP) were not significantly affected by dietary phosphorus levels $(P>0.05)$. 
Table 4. Plasma biochemical parameters of bighead carp fed with the experimental diets (Mean \pm S.E.M. $)^{1}$

\begin{tabular}{lllllllll}
\hline Diet & $A L B^{2}$ & $T P^{3}$ & $G / l^{4}$ & $T C^{5}$ & $T G^{6}$ & $A L T^{7}$ & $A S T^{8}$ & $A L P^{9}$ \\
\hline 1 & $12.38 \pm 0.36^{\mathrm{a}}$ & $30.93 \pm 0.77^{\mathrm{a}}$ & $4.94 \pm 0.39^{\mathrm{a}}$ & $2.13 \pm 0.07$ & $1.50 \pm 0.09$ & $2.70 \pm 0.30$ & $12.79 \pm 0.57$ & $43.10 \pm 4.13$ \\
2 & $11.99 \pm 0.30^{\mathrm{a}}$ & $31.33 \pm 0.82^{\mathrm{a}}$ & $5.53 \pm 0.43^{\mathrm{a}}$ & $2.30 \pm 0.07$ & $1.46 \pm 0.14$ & $2.21 \pm 0.25$ & $12.79 \pm 0.74$ & $41.89 \pm 4.95$ \\
3 & $12.88 \pm 0.35^{\mathrm{ab}}$ & $31.94 \pm 0.97^{\mathrm{ab}}$ & $5.85 \pm 0.23^{\mathrm{ab}}$ & $2.46 \pm 0.08$ & $1.81 \pm 0.11$ & $2.04 \pm 0.22$ & $12.53 \pm 0.94$ & $55.11 \pm 5.42$ \\
4 & $14.16 \pm 0.28^{\mathrm{b}}$ & $34.93 \pm 0.84^{\mathrm{b}}$ & $7.81 \pm 0.33^{\mathrm{c}}$ & $2.41 \pm 0.14$ & $1.48 \pm 0.12$ & $2.00 \pm 0.28$ & $12.45 \pm 0.83$ & $51.34 \pm 6.29$ \\
5 & $13.15 \pm 0.33^{\mathrm{ab}}$ & $33.57 \pm 0.65^{\mathrm{ab}}$ & $8.49 \pm 0.39^{\mathrm{c}}$ & $2.22 \pm 0.07$ & $1.37 \pm 0.13$ & $1.97 \pm 0.20$ & $11.51 \pm 0.96$ & $41.20 \pm 5.19$ \\
6 & $12.35 \pm 0.27^{\mathrm{a}}$ & $31.64 \pm 0.60^{\mathrm{a}}$ & $7.36 \pm 0.45^{\mathrm{bc}}$ & $2.10 \pm 0.10$ & $1.36 \pm 0.16$ & $2.62 \pm 0.31$ & $12.25 \pm 0.85$ & $47.32 \pm 6.19$ \\
\hline
\end{tabular}

${ }^{1}$ Data are means of triplicate; means in the same column sharing the same superscript letter are not significantly different determined by Tukey's test $(P>0.05)$.

${ }^{2}$ Albumin (ALB, g/L); ${ }^{3}$ Total protein (TP, g/L); ${ }^{4}$ Glucose (GLU, mmol/L); ${ }^{5}$ Total cholesterol (TC, $\mathrm{mmol} / \mathrm{L}) ;{ }^{6}$ Total triglyceride (TG, mmol/L); ${ }^{7}$ Alanine aminotransferase (ALT, U/L); ${ }^{8}$ Aspartate aminotransferase (AST, U/L); ${ }^{9}$ Alkaline phosphates (ALP, U/L).

Relative expression of SREBP-1 and FAS in the liver. These are presented in Figs. $3 \& 4$. Relative expression levels of sterol regulatory element binding protein (SREBP) -1 and fatty acid synthase (FAS) were significantly down-regulated when the dietary phosphorus levels were up to $1.32 \%$ and $1.59 \%$, and significantly lower than other groups $(P<0.05)$, while no significant differences were found among the other groups $(P$ $>0.05)$.

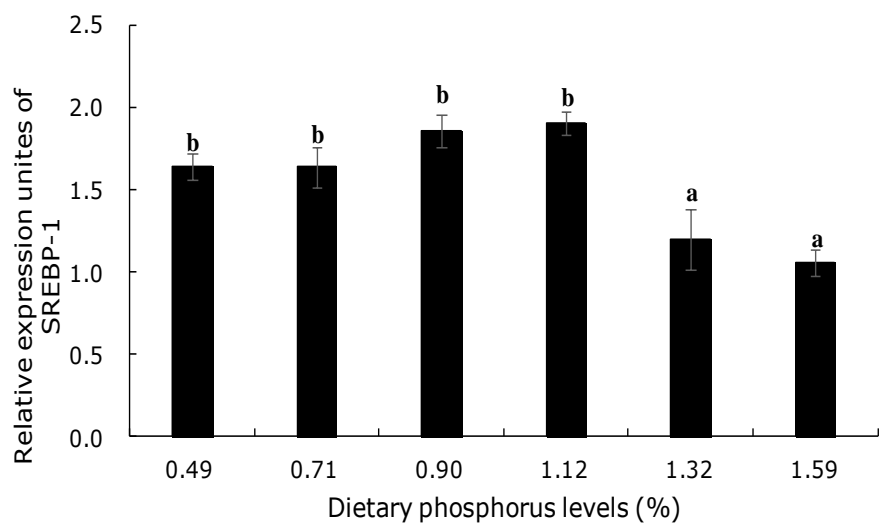

Figure 3. Relative expression levels of SREBP-1 of bighead carp fed with the experimental diets for 8 weeks. Values are means for nine fish per treatment, with standard errors represented by vertical bars. Mean values with unlike small letters were significantly different $(P<0.05)$.

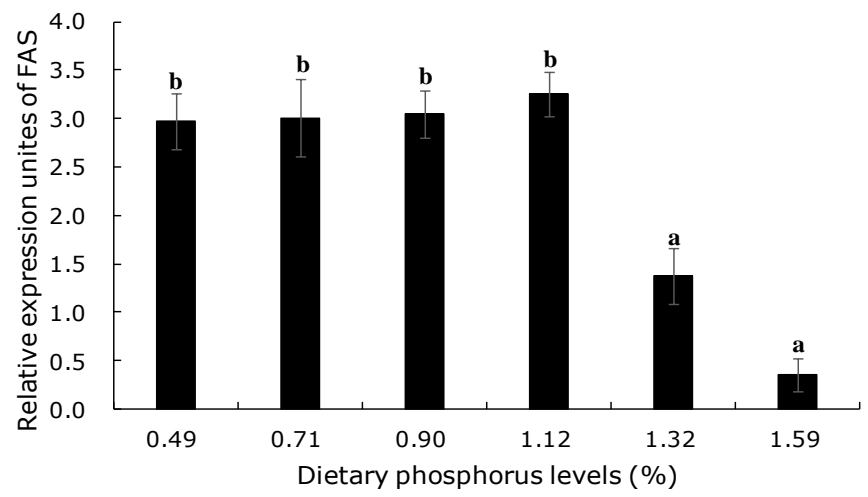

Figure 4. Relative expression levels of FAS of bighead carp fed with the experimental diets for 8 weeks. Values are means for nine fish per treatment, with standard errors represented by vertical bars. Mean values with unlike small letters were significantly different $(P<0.05)$. 


\section{Discussion}

Phosphorus is an essential nutrient for growth, skeletal development, and reproduction of fish (Shao et al., 2008). Phosphorus deficiency symptoms have been described in many fish species (Yuan et al., 2011). These including poor growth, reduced feed efficiency, and poor bone mineralization (Brown et al., 1993). In the present study, a phosphorusdeficient diet $(0.49 \%)$ showed poor growth and reduced feed efficiency, which agrees with reports on sunshine bass Morone chrysops, (Brown et al., 1993) and large yellow croaker (Mai et al., 2006). Our study showed that in fish fed $1.12 \%$ diet, growth performance improved significantly but based on WG and FCR we found that the optimal dietary phosphorus level was $1.16 \%$ in bighead carp. The result is similar for carp $(0.95 \%$ -1.10\%) (Ogino and Takeda, 1976), Atlantic salmon (1.0\%) (Åsgård and Shearer, 1997), but higher than for mirror carp Cyprinus carpio, (0.67\%) (Kim et al., 1998), Channel catfish $(0.40 \%)$ (Wilson et al., 1982) but lower than results reported for prawn Litopenaeus vannamei, (1.33\% and 2.0\%) (Deshimaru and Yone, 1978). These differences in the estimated phosphorus requirements for aquatic animals are probably due to specific species, diet composition, model used to determine the requirement, age, and density (El-Zibdeh et al., 1995; Zhang et al., 2017).

In the present study, crude protein and lipid content respectively, increased and then decreased with increasing dietary phosphorus, and was consistent with previous studies including channel catfish (Eya and Lovell, 1997) and grass carp ctenopharyngodon idella (Liang et al., 2012). Deficient phosphorus might cause impairment in oxidative phosphorylation, inhibition of TCA cycle, and cause acetyl-CoA. These changes may have inhibited lipid oxidation, and resulted in fish utilizing lower lipid levels as an energy source (Sakamoto and Yone, 1978); increased dietary phosphorus levels could also enhance nitrogen retention and increase protein accretion (Hegsted, 1974).

In fish physiological diagnoses, plasma biochemical parameters are usually used to determine the general health status (Davis, 2004). Blood TP and ALB content reflect the nutritional and metabolic status of fish (Ortuño et al., 2001). In this study, TP and ALB content increased when the dietary phosphorus level was $1.12 \%$. Similar results were found in yellow croaker (El-Zibdeh et al., 1995). It has been suggested that stress causes high serum glucose levels in fish species (Ming et al. 2012). In the present study, plasma glucose content was maximal when phosphorus level was $1.32 \%$, indicating that excess dietary phosphorus leads to nutritional stress in bighead carp. Blood AST and ALT are used as general indicators of liver function (Yamamoto, 1981). In the current study, AST and ALT activities were not significantly affected by dietary phosphorus levels suggesting that dietary phosphorus does not affect liver function.

SREBP-1 is the most important transcription factor that regulates lipid metabolism in various physiological and pathological conditions (Wang et al., 2015) and regulates the biosynthesis of fatty acid by regulating FAS (Jeon and Osborne, 2012). FAS is the sole enzyme capable of reductive de novo synthesis of long-chain fatty acids (Kuhajda et al., 1994), and can alter rates of biosynthesis and hydrolysis of fatty acids (Smith et al., 2003). In this study, down-regulated mRNA levels of SREBP-1 and FAS were observed in fish when dietary phosphorus was higher than $1.12 \%$, indicating that high dietary phosphorus levels inhibit the synthesis of fat and demonstrating that excess phosphorus releases fat deposition in this fish species. There is little information about the effect of dietary phosphorus on relative expression of SREBP-1 and FAS in fish species. However, the mechanisms of the way dietary phosphorus affects lipid metabolism is not well understood and needs to be further investigated.

In summary, phosphorus is essential for growth and lipid metabolism of bighead carp. Based on WG and FCR, the optimal dietary phosphorus level was determined to be $1.16 \%$ of the diet. Dietary phosphorus also affects lipid metabolism by regulating the expression levels of SREBP-1 and FAS. 


\section{Acknowledgment}

This study was supported financially by the Research and Development of Science and Technology Cooperation Project of Sichuan Province (NO. 2017JZ0009), and the Modern Agriculture Industrial Technology System special project-the National Technology System for Conventional Freshwater Fish Industries (CARS-46).

\section{References}

Åsgård T, and Shearer KD., 1997. The dietary phosphorus requirement of juvenile Atlantic salmon (Salmo salar) and its relationship to the phosphorus requirements reported for other fishes. Aquacult. Nutr., 3:17-23.

Beveridge, M.C.M., 1984. Cage and pen fish farming: carrying capacity models and environmental impact. FAO Fish. Tech. pp. 255, 131.

Boyd, C.E., 1971. Phosphorus dynamic in ponds. Proc. Annu. Conf. Southeast. Assoc. Game Fish Comm. 25:418-426.

Brown, M.L., Jr, F.J., and Iii, D.M.G., 1993. Dietary phosphorus requirement of juvenile sunshine bass, morone chrysops $\$ \times \mathrm{m}$. saxatilis $\odot$. Aquaculture, 113(4):355363.

Davis, K. B., 2004. Temperature affects physiological stress responses to acute confinement in sunshine bass (morone chrysops $\times$ morone saxatilis). Comparative Biochemistry and Physiology Part A, 139(4): 433-440.

Deshimaru, O., and Yone, Y., 1978. Requirement of prawn for dietary minerals. Bull. Japanese Soc. Sci. Fish., 44(8):907-910.

El-Zibdeh, M., Ide, K., Yoshimatsu, T., Matsui, S., and Furuichi, M., 1995. Requirement of yellow croaker nibea albiflora for dietary phosphorus. J Faculty of Agric.Kyushu University (Japan), 40(1-2): 147-155.

Eya, J. C., and Lovell, R. T., 1997. Available phosphorus requirements of food-size channel catfish (ictalurus punctatus) fed practical diets in ponds. Aquaculture, 154(3-4): 283-291.

Hegsted, D.M., 1974. Energy needs and energy utilization. Nutr. Rev., 32(2): 33-8.

Jeon, T. I., and Osborne, T. F., 2012. Srebps: metabolic integrators in physiology and metabolism. Trends in Endocrinol. Metabol., 23(2): 65-72.

Kim, J.D., Kim, K.S., Song, J.S., Lee, J.Y., and Jeong, K.S., 1998. Optimum level of dietary monocalcium phosphate based on growth and phosphorus excretion of mirror carp, cyprinus carpio. Aquaculture, 161(1-4): 337-344.

Kuhajda FP, Jenner K, and Wood FD, 1994. Fatty acid synthesis: a potential selective target for antineoplastic therapy. Proceedings of the National Academy Sciences, 91: 6379-6383.

Lall, S.P., 2002. The minerals. In: Halver, J.E., Hardy, R.W. (Eds.), Fish Nutr., 3rd ed. Academic Press, San Diego, CA, pp. 259-308.

Liang, J.J., Liu, Y.J., Tian, L.X., Yang, H.J., and Liang, G.Y., 2012. Dietary available phosphorus requirement of juvenile grass carp (ctenopharyngodon idella). Aquacult. Nutr., 18(2): 181-188.

Lieberman Davine M., 1996. Use of silver carp (hypophthalmichthys molotrix) and bighead carp (aristichthys nobilis) for algae control in a small pond: changes in water quality. J Freshwater Ecol., 11(4): 391-397.

Liu, B., Ge, X.P., Xie, J., Xu, P., He, Y.J., Cui, Y.T., Ming, J.H., Zhou, Q.L., and Pan, L.K., 2012. Effects of anthraquinone extract from Rheum officinale Bail on the physiological responses and HSP70 gene expression of Megalobrama amblycephala under Aeromonas hydrophila infection. Fish Shellfish Immunol., 32: 1-7.

Lovell, R.T., 1989. Nutrition and Feeding of Fish. Van Nostrand Reinhold, New York, NY. $260 \mathrm{pp}$.

Mai, K., Zhang, C., Ai, Q., Duan, Q., Xu, W., Zhang, L., and Tan, B., 2006. Dietary phosphorus requirement of large yellow croaker, Pseudosciaena crocea R. Aquaculture, 251(2): 346-353. 
Ming, J.H., Xie, J., Xu, P., Ge, X.P., Liu, W.B., and Ye, J.Y., 2012. Effects of emodin and vitamin $\mathrm{C}$ on growth performance biochemical parameters and two HSP70s mRNA expression of Wuchang bream (Megalobrama amblycephala Yih) under high temperature stress. Fish Shellfish Immunol., 32: 651-661.

National Research Council (NRC), 1993. Nutrient Requirements of Fish. National Academy Press, Washington, D.C.

Ogino, C., and Takeda, H., 1976. Mineral requirements in fish. iii. calcium and phosphorus requirements in carp. Nihon suisan gakkaishi, 42(7): 793-799.

Ortuño, J., Esteban, M.A., and Meseguer, J., 2001. Effects of short-term crowding stress on the gilthead sea bream (Sparus aurata L.) innate immune response. Fish Shellfish Immunol., 11: 187-197.

Pfaffl, M.W., 2001. A new mathematical model for relative quantification in real-time RT-PCR. Nucleic Acids Res., 29: 2002-2007.

Sakamoto, S., and Yone, Y., 1978. Effect of dietary phosphorus level on chemical composition of red sea bream. Nsugaf, 44(3): 227-229.

Shao, Q., Ma, J., Xu, Z., Hu, W., Xu, J. and Xie, S., 2008. Dietary phosphorus requirement of juvenile black sea bream, Sparus macrocephalus. Aquaculture, 277: 92100.

Smith, S., Witkowski, A., and Joshi, A.K., 2003. Structural and functional organization of the animal fatty acid synthase. Progress in Lipid Research, 42: 289-317.

Tong, J., and Sun, X., 2015. Genetic and genomic analyses for economically important traits and their applications in molecular breeding of cultured fish. Science China Life Sciences, 58 (2): 178-186.

Wang, H., Zhu, L., Hao, J., Duan, H., Liu, S., and Zhao, S., 2015. Co-regulation of srebp-1 and mtor ameliorates lipid accumulation in kidney of diabetic mice. Exper. Cell Res., 336(1): 76-84.

Wang, L.N., Liu, W.B., Lu, K.L., Xu, W.N., Cai, D.S., Zhang, C.N., and Qian, Y., 2014. Effects of dietary carbohydrate/lipid ratios on non-specific immune responses, oxidative status and liver histology of juvenile yellow catfish Pelteobagrus fulvidraco. Aquaculture, 426-427: 41-48.

Watanabe, T., Satoh, S., and Takeuchi, T., 1988. Availability of minerals in fishmeal to fish. Asian Fisheries Society, 1: 175-195.

Wilson, R.P., Robinson, E.H., Rd, G.D., and Poe, W.E., 1982. Dietary phosphorus requirement of channel catfish. J Nutr., 112(6): 1197-1202.

Yamamoto., 1981. Determination of toxicity by biochemical method. In: Egami, N. (Ed.), Fishes as Laboratory, Chapter 4. Soft Science, Tokyo, Japan, pp. 568-574.

Yuan, Y.C., Yang, H.J., Gong, S.Y., Luo, Z., Yu, D.H., Yan, J.L. and Y, X.F., 2011. Dietary phosphorus requirement of juvenile Chinese sucker, Myxocyprinus asiaticus. Aquacult. Nutr., 17: 159-169.

Zhang, Y.F., Yue, Y.R., Tian, L.X., Liu, Y.J., Wang, A.L., Yang, H.J., Liang, G.Y., Zhang, K., Xie, J., Yu, D. G., Wang, G. J., Yu, E. M., and Gong, W. B., 2017. A comparative study on the budget of nitrogen and phosphorus in polyculture systems of snakehead with bighead carp. Aquaculture, 483: 69-75.

Ye, C.X., 2015. Dietary Phosphorus Requirements of Juvenile Hybrid Tilapia (Oreochromis niloticus $\& \times$ O. Aureusळ) Fed Fishmeal-free Practical Diets. Isr. J. Aquacult.-Bamidgeh, 67:1179, 1-12. 